\title{
Pierre-W. Boudreault, Denis Jeffrey (sous la direction de), Identités en errance. Multi-identité, territore impermanent et être social
}

\section{Simona Rossi}

\section{(2) OpenEdition}

\section{Journals}

Edizione digitale

URL: http://journals.openedition.org/studifrancesi/9684

DOI: 10.4000/studifrancesi.9684

ISSN: 2421-5856

\section{Editore}

Rosenberg \& Sellier

\section{Edizione cartacea}

Data di pubblicazione: 1 décembre 2007

Paginazione: 699-700

ISSN: 0039-2944

\section{Notizia bibliografica digitale}

Simona Rossi, «Pierre-W. Boudreault, Denis Jeffrey (sous la direction de), Identités en errance. Multiidentité, territore impermanent et être social», Studi Francesi [Online], 153 (LI | III) | 2007, online dal 30 novembre 2015, consultato il 10 janvier 2021. URL: http://journals.openedition.org/studifrancesi/9684 ; DOI: https://doi.org/10.4000/studifrancesi.9684

Questo documento è stato generato automaticamente il 10 janvier 2021.

\section{cc) $($ ) $\ominus$}

Studi Francesi è distribuita con Licenza Creative Commons Attribuzione - Non commerciale - Non opere derivate 4.0 Internazionale. 


\title{
Pierre-W. Boudreault, Denis Jeffrey (sous la direction de), Identités en errance. Multi-identité, territore impermanent et être social
}

\author{
Simona Rossi
}

\section{NOTIZIA}

PIERRE-W. BOUDREAULT, DENIS JEFFREY (sous la direction de), Identités en errance. Multiidentité, territore impermanent et être social, Québec, Les Presses de l'Université Laval, 2007, pp. 201.

1 Risultato degli elaborati studi di due gruppi di ricerca, «Identité, espace et politique» e «L'imaginaire dans l'expérience collective», entrambi membri dell'Associazione Internazionale dei Sociologi di Lingua Francese (A.L.S.L.F), questo testo parte da un presupposto più che evidente nella realtà attuale: il forte rifiuto della società per tutto ciò che può rappresentare un ostacolo alla libertà personale, di azione e di pensiero. Gli autori s'interrogano sulle dinamiche di tale fenomeno, mostrando che da un lato ci si trova di fronte a un'innegabile conquista, mentre dall'altro «l'individu risque l'erranee s'il ne trouve pas l'écho ni le miroir capables de lui indiquer la mesure de ses limites» (p. xI). È proprio la perenne errance identitaire che caratterizza l'individuo post-moderno a costituire il fulcro dell'indagine sociologica qui proposta: quali sono gli elementi sociali e psicologici che la provocano? Quali le sfaccettature ad essa legate? Quali esiti possibili bisogna aspettarsi in futuro?

2 I ricercatori che hanno lavorato a questo volume sono comunque tutti concordi nel ritenere che l'assoluta mancanza di regole morali di ordine collettivo non giovi affatto alla definizione individuale dell'identità. L'epoca contemporanea ha perso ormai ogni punto di riferimento, non conosce più il significato di condivisione, i sistemi simbolici 
comuni si sono sgretolati, la famiglia è divenuta uno spazio domestico fragile e facilmente soggetto a nevrosi, per questo l'individuo sceglie sempre più spesso di chiudersi in sé stesso, lasciando fuori gli Altri che, come lui, compiono un cammino solitario e del tutto "libero". Ma cosa resta dell'identità - che si costruisce da sempre in relazione al contatto con l'Altro - quando gli altri, appunto, si posizionano all'esterno del sé, in un mondo peraltro percepito come étranger?

3 I saggi che compongono le tre parti di quest'opera hanno proprio l'obiettivo di rispondere a tale quesito. La prima, intitolata «L'identité en tension», considera come la post-modernità, a differenza delle epoche che l'hanno preceduta, abbia messo in atto dei meccanismi di distruzione dell'identità più che di costruzione: la rottura con le istituzioni tradizionali, infatti, non ha prodotto né nuovi valori né nuove norme sociali, ma semplicemente individui liberi che, «sans bornes, sans élan» (p. xvI), non sanno comunque esercitare e gestire la libertà di cui godono. La seconda parte, dedicata a «Vitalité et territoire impermanent», s'interessa alla formazione di luoghi di riferimento identitario nel momento in cui lo spazio diventa instabile e polisemico, privo di unicità. Gli autori mettono in luce soprattutto l'importanza della strada quale spazio vitale e vacante per tutti quegli individui, come gli immigrati, che, non trovando alcun riferimento sociale in cui identificarsi, probabilmente si sentono essi stessi "vacanti" e sono quindi alla ricerca di un luogo che li rispecchi. Un'interessante analisi a parte è dedicata anche ai tanto attuali e problematici comportamenti giovanili nelle banlieues, la cui insorgenza sarebbe legata proprio alla perdita di valori identitari comuni trasmessi dall'alto: folte schiere di giovani "liberi" e disorientati, così, non troverebbero altro modo, per esprimere il loro disagio, che la violenza esterna. La terza parte, dedicata al tema dell'être social et individu hypermoderne, offre una panoramica sui nuovi miti "liberi" e contemporanei in grado di produrre senso di aggregazione: la cultura di strada legata a particolari musiche e attività sportive, ad esempio, lo spazio urbano concepito come scuola di formazione e teatro politico, la comunicazione virtuale, la "letteratura" in rete etc.

4 L'uomo contemporaneo, quindi, continua a respingere l'idea di valori universali a cui aderire, ma non smette comunque di cercare soluzioni "aggreganti". Identités en errance costituisce un testo davvero originale che, con l'ausilio di un'esposizione chiara, induce a riflettere su temi di pubblico dominio che - per difesa o per superficialità? - sfuggono alla riflessione e all'attenzione collettive. 